breeds and crosses for beef production; from examination of the seasonal changes in management in relation to milk yields to the assessment of progeny test results and to the effects of inbreeding on performance in dairy cattle; from investigations on nutritional levels in late pregnancy, through others on meat quality and on body size in reciprocal crosses, to analyses of the factors of flock size and flock duration in the population genetics of sheep. There are also reports of work on the use of partial records in poultry selection, on the experimental shortening of the generation interval in rabbits by gonadotrophin treatment, and preliminary accounts of comparisons of different sources of vitamins $A$ and $D$ in relation to the fattening of pigs and of $X$-ray studies on the structure and variation of the vertebral column in the Welsh breed of pigs.

The "Proceedings" are well edited, and appear in pleasing and convenient format : their diffuse contents may suggest that in this step of policy the riser is too high too early in the stairway to the platform of a British Journal of Animal Production. On the other hand, the tread seems sound, and it may well be that the Society can now move up and on to achieve this particular aim, without side-tracking its other aims, of which the study of local methods and practices of animal production is by no means the least valuable and of which all record has been somewhat regrettably omitted for 1953 and 1954 .

J. E. Nichols

\section{BERLIN ACADEMY OF SCIENCES}

'HE first 'annual meeting' of the Deutsche Academie der Wissenschaften zu Berlin to be held since the War took place during March 28April 2. Until 1939, there had been an annual celebration of the first president of the Academy, G. W. Leibniz. The present meeting was a revival of this tradition. Some four hundred and seventy scientists from Eastern Germany and some eighty scientists from other countries, including Western Germany, took part in the meetings.

The opening session was held in the Grosser Festsaal im Haus der Ministerien and was addressed by the president of the Academy, Prof. W. Friedrich, well known as the co-discoverer, with von Laue and Knipping, of the diffraction of X-rays by crystals. Government representatives present included the president of the Volkskammer, Dr. Dieckmann, and the Prime Minister, Otto Grotewohl. After Dr. Friedrich had spoken, each of the secretaries of the five sections of the Academy reported on his own section. Last year a considerable reorganization of the Academy took place so that the subjects are re-grouped in the following way: (1) mathematics, physics, engineering ; (2) chemistry, geology, biology; (3) medicine ; (4) language, literature and art; (5) philosophy, history, law, economics. (The inclusion of non-natural science subjects within the purview of the Academy follows a common Continental custom of using the word science in the meaning of 'scientas'.) The secretaries' reports all showed a very considerable development of the work done by the various institutions and laid stress on the need for ensuring a proper application to industry of the results of scientific research. The present secretaries of the sections are, respectively, Profs. Rompe, Noack, Lohmann, Frings and Unverzagt. The second full session was addressed by Prof. Kurt Mothes on "The Roots of Plants-a Chemical Factory of a Particular Kind", and by Prof. Wolfgang Steinitz, vice-president of the Academy, on "Songs and Fables as Expressions of the Spirit of a People". Then followed two and a half days of conferences on specialized subjects. These included "Physics and Chemistry of Crystals", "Metallurgy of Iron", "Radio-astronomy", "Fibres from Synthetic High Polymers", "Results and Problems of Biochemical Research", "Questions concerning Cancer Research and Treatment", "Dialect Study", "Songs, Fables, Proverbs and Sayings, as expressions of the Spirit of a People". There were also lectures by Prof. Gordon Childe (London) and Prof. Hans Jürgen Eggers (Hamburg) in the Institute for Pre- and Early-History, and by Prof. Johannes Straub (Bonn) in the Commission for Spätantike Religionsgeschichte. Visits were arranged for all the visitors to the laboratories and institutions in which they were interested. An informal reception was arranged on the first evening and a dinner party in the great hall in the Haus der Ministerien at the conclusion of the meetings. A two-day excursion to Weimar, famous for its associations with poets, was arranged for those who had time to go.

Certain general impressions may be worth recording. The scientific institutions and those who work in them are flourishing; the material means both in terms of research facilities and salaries are good. There is a widespread desire for more contact with scientists in other countries, and a wish to be able to attend international conferences more easily than is possible at present. The publications of the Akademie Verlag include a considerable number of translations of important modern Soviet books, and for those who cannot read Russian the German Academy is likely to be of great service through those translations. Finally, it should be said that the friendliness and hospitality shown by our hosts were all that could be desired.

W. A. Wooster

\section{NATIONAL SCIENCE FOUND- ATION, WASHINGTON, D.C. REPORT FOR 1953-54}

$T$

HE fourth annual report* of the National Science Foundation, Washington, D.C., covers the year ended June 30, 1954, and includes, besides the report of the director, Dr. A. T. Waterman, a foreword by Chester J. Barnard, chairman of the National Science Board, and appendixes listing the personnel of the Board and its advisory panels and committees and the basic research grants made during the year, as well as a complete list of individuals awarded fellowships in 1954. Mr. Barnard emphasizes in his foreword that the central task of the Foundation is the promotion or cultivation of science in the United States, and in this connexion notes the importance of incentives for the pursuit of scientific careers. A deep, personal and indefatigable interest in scientific discovery is the primary and indispensable incentive; but relative freedom, adequate remuneration and public esteem are also important, and lavish and indiscriminate expenditure will not counterbalance conditions which discourage initiative, imagination

* National Science Foundation. Fourth Annual Report for the Fiscal Year ending June 30,1954 . Pp. $1 \mathrm{x}+138+4$ plates. (Wash-
ington, D.C. : Government Printing Office, 1954.) 50 cents. 